THURSDAY, JANUARY 2, 1873

\section{THE GOVERNMENT AND THE ARCTIC EXPEDITION}

THE Arctic Expedition is undoubtedly the question of 1 the day; or, seeing that the wheels of the gods have brought us to the commencement of another annual round, it may be really called the question of the yearthat is, of the coming one. We may as well confess at once that we consider it quite worth all the attention it is likely to receive, either at the hands of Her Majesty's Ministers or from the public at large.

It is understood that the Government are at the present moment considering their decision, and it is because this is so that we venture to return to the subject, as there is an idea that the matter has not been put before the Government in the strong manner that it might have been; and the idea is true to a certain extent. But the blame, if any blame there be, attaches more to our scientific system, or rather our want of all system, than to any individuals. No doubt the Royal Society should have had a little more, and the Geographical Society a little less to say at the deputation that waited upon the Government, because we believe that the time has come when both Ministers and people will demand the widest possible basis of research for such an expedition; and that the widest possible basis was not put forward has since been clearly shown by Prof. Balfour Stewart, who has written to the Times on the subject. His letter is so important that we give it almost in extenso. He writes:-

"We have pursued terrestrial meteorology and magnetism now for some time, but until lately we have been rewarded with little apparent success. We are at last, however, beginning to understand the great importance of these studies, and to see the true path in which they ought to be pursued.

"Proofs of an intimate and mysterious connection between the sun and the earth are rapidly accumulating from various quarters, and the latest instance is one which is surely well worth the attention of all practical men. : "I allude to the discovery by Mr. Charles Meldrum, of Mauritius, that the years when most spots are observed on the sun's surface are also those of most cyclones in the Indian Ocean. Furthermore, a similar connection between the state of the sun's surface and the magnetism of the earth was noticed twenty years ago by Sir Edward Sabine, the late president of the Royal Society.

"Now, surely we ought to inquire into the nature of this mysterious connection, and, if necessary, we ought to spend both means and trouble in the pursuit of such an inquiry?

"What, then, ought to be done? The line of action is surely that recently suggested by Mr. Norman Lockyer. We ought, in the first instance, to scrutinise the sun's surface with all the appliances we can command, with the view of recording the meteorological changes which are there occurring; and in the next instance we ought to do the same with regard to our own earth. To do the first it will be necessary to establish a proper physical observatory; and to do the second it is essential that we should become better acquainted with the less frequented regions of our globe, which are in many respects the most important. We must especially greatly extend our knowledge of the northern regions, and not of those alone but of the less frequented oceanic regions also.

"Now, these are objects which can only be accomplished by means at the disposal of Government ; for it will be in vain to expect whalers to supply us with the knowledge we desire of these northern regions, and it will be equally in vain to expect merchantmen to cruise about in the less frequented oceanic latitudes in order to increase our acquaintance with their meteorology.

"We have before us the splendid possibility of predicting the nature of seasons; but surely we cannot expect that Nature, who is usually so reticent, will disclose her secrets to a nation or a race who will not take reasonable trouble to complete their knowledge of the physics of the earth?"

Now there is no man of science who will gainsay these remarks coming from so distinguished an authority ; and it is quite obvious that if the promoters of the expedition had taken a little more trouble and given a little more publicity to their action, the deputation might have been able to enforce its main arguments by this and other additional "reasons" given by other eminent men of science. Before it is too late, then, and another year is lost, it is to be hoped that the views so ably expressed by Dr. Stewart and held by all who have studied the subject in which he is such an acknowledged master, will be placed before the Government in the most forcible manner possible. The sun cycle to which he refers and which we now know governs cyclones and rainfall in certain parts of the earth, may it not also have something to say to the very passage to the Pole itself? May not the rainy mild seasons, which in the northern temperate zone, have more than once, to say the least, followed the sun-spot maximum, influence the dense masses of polar ice and make navigation more easy? If no one can answer this question, we have in this point alone a sufficient "reason" for undertaking the expedition; while the study of the whole phenomena including the spectrum of the aurora would furnish another, if the mere number of questions were to have weight ; and it is curious to notice, that while we remain so ignorant of the nature of whole ranges of polarphenomena in the case of our own planet, the solar polar phenomena have recently been investigated by Prof. Respighi, with marvellous success, by means of the new method.

Sooner or later the polar phenomena of the earth must be studied, and their variations laid down in curves. Modern science demands this, and every year now lost it may take ten to recover. The question is, is England to have a hand in this matter? It is not a question between A's or B's pet theory of getting to the Pole. Will the Government refuse the expedition, now that Admiral Richards, the distinguished Hydrographer of the Admiralty, an officer in whose hands we may with safety leave the claims of cosmical science, has volunteered to command it? In the centuries to come, it will be told how England, in 1870 and 1871 , sent out expeditions to observe eclipses of the sun, how in 1872 she sent out the Challenger, how in 1874 she sent out expeditions to observe the Transit of Venus. Why, then, should $\mathbf{x} 873$ not be thus distinguished? We firmly believe that the Government have obtained a firmer hold upon the best side of Englishmen by their aid to these scientific expeditions than by all their merely political measures; and surely a universal approval, separated as far as possible from a party feeling, is the best thing Government can strive to obtain.

We believe a statement that the Government has refused the expedition will be received with universal disappointment by every class of Englishmen, to whom the memories which dwell round the name of Captain Cook and a whole navy of Arctic explorers in the past are very dear and a source of pardonable pride. 